\title{
Biosynthesis and Structural Characterization of Levan by a Recombinant Levansucrase From Bacillus Subtilis ZW019
}

\section{Jingyue Wang}

Tianjin University

\section{Xinan Xu}

Tianjin University

Fangkun Zhao

Tianjin University

Nan Yin

Tianjin University

\section{Zhijiang Zhou}

Tianjin University

\section{Ye Han ( $D$ Hanye@tju.edu.cn )}

School of Chemical Engineering and Technology, Tianjin University https://orcid.org/0000-0003-16770184

\section{Research Article}

Keywords: Levan, Biosynthesis, Recombinant levansucrase, Structural characterization

Posted Date: May 18th, 2021

DOl: https://doi.org/10.21203/rs.3.rs-511002/v1

License: (9) This work is licensed under a Creative Commons Attribution 4.0 International License. Read Full License 


\section{Abstract}

Objectives

The yield of levan extracted from microbial fermentation broth is low, so in vitro catalytic synthesis of levan by levansucrase is expected to be one of the industrial production approaches of levan.

Results

A recombinant plasmid Pet-28A-AcmA-Z constructed in the previous study was used to produce levansucrase. The recombinant levansucrase could be easily purified in one step and the purified enzyme had a single band clearly visible in SDS-PAGE. The conditions for enzymatic reactions was optimal at pH 5.2 and $40{ }^{\circ} \mathrm{C}$, and the activity of enzymes was stimulated by $\mathrm{K}^{+}$and $\mathrm{Ca}^{2+}$. The yield of levan biosynthesis from $10 \%(\mathrm{w} / \mathrm{v})$ sucrose with $6.45 \mathrm{U} / \mathrm{g}$ sucrose of levansucrase was $30.6 \mathrm{~g} / \mathrm{L}$. The molecular weight of the levan was about $1.56 \times 10^{6} \mathrm{Da}$, as measured by GPC. HPIC analysis showed that the monosaccharide composition of the levan was fructose and glucose. The results of FTIR and NMR analysis indicated that the polymer produced by the recombinant levansucrase was $\beta-(2,6)$ levan.

Conclusions

The results of this study provide a basis for large-scale production of levan by enzymatic method.

\section{Introduction}

Levan is a fructan biopolymer, and its fructose chain is formed by $\beta-(2,6)$ glycosidic bonds with some $\beta$ $(2,1)$ linked branch chains (Bouallegue et al. 2020a; Xavier and Ramana 2017). Due to its excellent biocompatibility, biodegradability, renewability, eco-friendliness, and human compatibility, levan has a wide range of applications in the fields of food and pharmaceuticals (Barone and Medynets 2007; Chiang et al. 2009). In the food industry, levan is used as a stabilizer, encapsulating agent, water-holding agent, surface-finishing agent, thickener, emulsifier, flavor carrier, and prebiotic sweetener (Jang et al. 2001). In addition, levan can also increase the shelf life of food and be used as a fat substitute (Haddar et al. 2021). In the field of pharmaceuticals, levan have anti-hyperglycemia, anti-diabetes, anti-oxidation, antivirus (Esawy et al. 2011), cholesterol-lowering (Yamamoto et al. 1999), anti-tumor (Srikanth et al. 2015a) and immunomodulatory bioactivities.

Levan is naturally produced by plants or microorganisms. Microbial levans have a much larger molecular weight (2 to $100 \mathrm{MDa}$ ) than plant-produced levans (2 to $33 \mathrm{kDa}$ ). Due to the low content of levan in plants and the high cost of natural extraction and separation, levan is not suitable for industrial production. So far, the production of levan is mainly biosynthesized by levansucrase using sucrose as substrate. Many microorganisms can produce levan, such as Zymomonas (Poli et al. 2009), Bacillus (Shih et al. 2010), Pseudomonas (Poli et al. 2009), and Acetobacter xylinum (Srikanth et al. 2015b), but most of their 
production is too low to meet commercial needs. Therefore, levan production by enzymatic method may be an effective choice to solve the problem of low yield of wild strains.

In this study, we used the pre-constructed genetically engineered bacteria Escherichia coli BL21 to produce levansucrase (Genbank MT038999). The effects of temperature, $\mathrm{pH}$, and metal ions on the activities of the purified recombinant enzyme were investigated to evaluate its potential to synthesize levan. The polymer was analyzed by means of high-performance ion chromatography (HPIC), Fourier transform infrared (FTIR), nuclear magnetic resonance (NMR) techniques. The structure of the biosynthetic product was determined to be levan-type fructan.

\section{Materials And Methods}

\subsection{Bacterial Strains and culture conditions details}

E. coli strains DH5a and BL21 were cultivated aerobically at $37^{\circ} \mathrm{C}$ in lysogeny broth (LB). Restriction endonucleases, Prime STAR Max DNA Polymerase, and DNA Ligation Kit were obtained from TaKaRa Biotechnology Co., Ltd. (Dalian, China) or New England BioLabs (Beijing, China). The DNA primers and Plasmid Mini Kit were obtained from Shanghai Sangon Biological Engineering Technology \& Services Co., Ltd. (Shanghai, China). All other reagents were of analytical grade and were commercially available unless otherwise indicated.

\subsection{Gene cloning, expression and purification of the recombinant levansucrase}

In the previous study, we have constructed a levansucrase expression system using $E$. coli BL21 as the host (Wang et al. 2021). Briefly, the plasmid Pet-28A-AcmA-Z was used to clone the levansucrase gene from Bacillus subtilis ZW019, and the recombinant plasmid was transformed into E. coli BL21 by the heat shock method using chemically competent cells to construct the recombinant genetic engineering bacterium. The cells were then harvested by centrifugation at $12,000 \mathrm{rpm}$ for $20 \mathrm{~min}$ at $4^{\circ} \mathrm{C}$, and the precipitated fractions were labeled as intracellular components. The intracellular components were washed twice with $50 \mathrm{mM}$ Tris/HCL buffer $(\mathrm{pH} \mathrm{7.0)}$ ) and subsequently disrupted by ultrasonic oscillation. The cellular debris and unbroken cells were separated by centrifugation at $12,000 \mathrm{rpm}$ for $25 \mathrm{~min}$ at $4^{\circ} \mathrm{C}$. The supernatant after centrifugation was labeled as the source of levansucrase, and the precipitate was labeled as inclusion bodies. The intracellular enzyme was purified by using GEM particles as purification material and Acma as purification label (Zhao, et al. 2020). After SDS-PAGE gel electrophoresis analysis, the correct expression of the enzyme was confirmed.

\subsection{Measurement of the levan formation activity of levansucrase}

In order to determine the levan formation activity, $1 \mathrm{ml} 5 \%$ phenol and $5 \mathrm{ml}$ concentrated sulfuric acid were added to the reaction system. The solution was placed at room temperature for $20 \mathrm{~min}$, and then the 
absorbance was measured at $490 \mathrm{~nm}$ by UV-VIS Spectrophotometer (MAPADA, V-1800).

\subsection{Effect of temperature, $\mathrm{pH}$, metal ions on the activity of the recombinant levansucrase}

The optimum temperature for the activity of levansucrase was detected by cultivating the reaction mixture at $20.0-60.0^{\circ} \mathrm{C}$ at $\mathrm{pH} 5.2$ sodium acetate-acetate buffer using sucrose as the substrate $(10 \%$ $\mathrm{w} / \mathrm{v})$, and the optimum $\mathrm{pH}$ for enzyme activity was tested at $\mathrm{pH}$ ranges (4.6-5.6). The effect of metal ions was detected by preprocessing the levansucrase in the 50 sodium acetate-acetate buffer $(\mathrm{pH} 5.2)$ containing $5 \mathrm{mM}$ or $50 \mathrm{mM}$ of $\mathrm{K}^{+}, \mathrm{Ca}^{2+}, \mathrm{Cu}^{2+}, \mathrm{Mg}^{2+}, \mathrm{Fe}^{2+}, \mathrm{Fe}^{3+}, \mathrm{Ba}^{2+}, \mathrm{Zn}^{2+}, \mathrm{Ni}^{2+}$ and $\mathrm{Mn}^{2+}$ at $40^{\circ} \mathrm{C}$ for $2 \mathrm{~h}$. The activity of the preincubated sample at the most suitable conditions was taken as $100 \%$. All the experiments were performed in triplicate, and the error was expressed as the standard deviation of the three measurements.

\subsection{Determination of kinetic parameters}

Kinetic parameters of the levansucrase reactions were determined by varying the sucrose concentration $(0.0078-0.125 \mathrm{M})$ at $40^{\circ} \mathrm{C}$ and $\mathrm{pH}$ 5.2. We used DNS (3,5-dinitrosalicylic acid) method to determine the released total reducing sugar concentrations (Miller 1959). Data were fitted to the standard MichaelisMenten formula.

\subsection{Preparation and purification of levan}

The crude polysaccharide solution after the enzyme reaction was centrifuged at $4{ }^{\circ} \mathrm{C} 8,000 \mathrm{rpm}$ for 30 min. The supernatant was added with three times the volume of precooled $95 \%(\mathrm{v} / \mathrm{v})$ ethanol, and the polysaccharide was precipitated overnight at $4{ }^{\circ} \mathrm{C}$. Then the polysaccharide was centrifuged according to the above conditions and redissolved in an appropriate amount of ultrapure water. The redissolved solution was dialyzed with ultrapure water at $4{ }^{\circ} \mathrm{C}$ for $72 \mathrm{~h}$ in a dialysis bag with a molecular weight of 14 $\mathrm{kDa}$, and the water was changed every $8 \mathrm{~h}$. Finally, the polysaccharide sample was obtained by lyophilization.

\subsection{Monosaccharide Composition Analysis}

In this study, high-performance ion chromatography (HPIC, ThermoFisher ICS5000) was used to determine monosaccharide composition. The 13 kinds of monosaccharide standard (fucose, rhamnose, arabinose, galactose, glucose, xylose, mannose, fructose, ribose, galacturonic acid, glucuronic acid, guluronic acid, and mannuronic acid) were prepared into $10 \mathrm{mg} / \mathrm{ml}$ standard solution, respectively. $4 \mathrm{mg}$ of the sample was put into ampoule, and $1 \mathrm{ml} 2 \mathrm{~mol} / \mathrm{L}$ trichloroacetic acid (TFA) was added into it. The ampoule filled with the solution was put into an oven for hydrolysis for $2 \mathrm{~h}$ under the condition of $100{ }^{\circ} \mathrm{C}$. The acid hydrolysis solution of $200 \mu \mathrm{L}$ was transferred to a $1.5 \mathrm{~mL}$ EP tube for nitrogen blowing and drying, and $1 \mathrm{~mL}$ water was added for vortex mixing. The solution was centrifuged at 12, $000 \mathrm{rpm}$ for 5 min. The supernatant was added into IC for analysis. The detector used for ion chromatography analysis was an electrochemical detector. Chromatographic column type was DionexCarbopacTMPA20 (3*150) 
and the detection temperature was $30^{\circ} \mathrm{C}$. Mobile phase: $\mathrm{A}: \mathrm{H}_{2} \mathrm{O} ; \mathrm{B}: 250 \mathrm{mM} \mathrm{NaOH} ; \mathrm{C}: 50 \mathrm{mM} \mathrm{NaOH}$ \& $500 \mathrm{mM} \mathrm{NaOAC}$. The flow rate was $0.3 \mathrm{ml} / \mathrm{min}$ and the injection volume was $5 \mu \mathrm{L}$.

\subsection{Levan structural characterization and identification methods}

\subsubsection{Molecular weight and purity of levan}

The average molecular weight and purity of the levan were determined by gel permeation chromatography (GPC, Waters 1515) with Waters 2414 Refractive Index Detector. The ULTRAHYDROGEL 120, 250 and 500 PKGD columns were eluted with $0.1 \mathrm{M} \mathrm{NaNO}_{3}$ at a flow rate of $1 \mathrm{~mL} / \mathrm{min}$. Samples (25 $\mathrm{mg} / \mathrm{L}, 50 \mu \mathrm{L}$ ) were injected into the column. PEG standard compounds (Mp 330000, 176000, 82500, $44000,25300,20600,12600,7130,4290,1400,633,430 \mathrm{KDa}$ ) were provided by Polymer Standards Service-USA Inc.

\subsubsection{Scanning electron microscope (SEM) of levan}

The surface morphology of the levan was obtained by Scanning Electron Microscope (SEM, SU8020) technique. Freeze-dried pure levan was fixed to the SEM stubs with double-faced adhesive tape and coated with conductive gold in an ion sputtering apparatus. The microstructures of samples with different magnification were observed at an accelerating voltage of $10 \mathrm{kV}$. In this study, the SEM images of levan samples at magnification $400 \times \otimes 1000 \times \varangle 2000 \times$ were obtained.

\subsubsection{Atomic force micrograph (AFM) of levan}

The surface morphology and roughness of levan were obtained by Atomic force micrograph (AFM, Bruker Multimode8) analysis. The levan solution with a concentration of $1 \mathrm{mg} / \mathrm{ml}$ was prepared and stirred continuously for $1 \mathrm{~h}$ at $40{ }^{\circ} \mathrm{C}$ in an airtight bottle. Once cooled to room temperature, $5 \mu \mathrm{L}$ of levan solution was absorbed into the mica sheet. The AFM images of levan were obtained in tapping mode after drying at room temperature.

\subsubsection{Fourier-transform infrared spectroscopy (FT-IR)}

Fourier-transformed infrared spectroscopy is a common method for the determination of functional groups presented in levan. The levan and $\mathrm{KBr}$ powder were thoroughly mixed in a ratio of 1:100 to make a $1 \mathrm{~mm}$ thickness $\mathrm{KBr}$ pellet. The absorption spectrum of levan was recorded on a Thermo IS5 instrument (America) in the region of $4000-400 \mathrm{~cm}^{-1}$.

\subsubsection{Nuclear magnetic resonance spectroscopy (NMR)}

Nuclear magnetic resonance spectroscopy is a convenient method to analyze the advanced structure of polysaccharides, which can provide more detailed information and can be reused without destroying the polysaccharide samples. ${ }^{1} \mathrm{H}$ and ${ }^{13} \mathrm{C}$ NMR spectrum of the levan solution were recorded using a Bruker $600 \mathrm{M}$ spectrometer (Switzerland). $20 \mathrm{mg}$ purified and freeze-dried levan was dissolved in $\mathrm{D}_{2} \mathrm{O}$, dissolving 
and lyophilizing repeatedly to realize the exchange of $H$ and $D$. The prepared sample was sealed in an NMR tube. All the experiments were performed at room temperature and all the data were analyzed with MestRenova software.

\section{Results And Discussion}

\subsection{Purification of the recombinant levansucrase}

In order to purify the protein, the GEM particles were combined with the Acma-labeled recombinase, centrifuged at $4^{\circ} \mathrm{C} 12,000 \mathrm{rpm}$ for $30 \mathrm{~min}$ to collect the precipitate and dissolved in the constant volume of Tris/ $\mathrm{HCl}(\mathrm{pH}$ 7.2) buffer solution. As shown in Fig. 1, the purified enzyme had a single band clearly visible in SDS-PAGE (between $80 \mathrm{kDa}$ and $58 \mathrm{kDa}$ ), indicating that no impurities were introduced in the purification process. GEM particle purification is a promising method, which can save purification time, simplify operation and decrease activity loss compared with traditional purification methods (Zhao et al. 2020).

\subsection{Effect of temperature, $\mathrm{pH}$, metal ions on the levan formation activity of the recombinant levansucrase}

The levan biosynthesis ability of the recombinant enzyme was evaluated at various temperatures, ranging from $20^{\circ} \mathrm{C}$ to $60^{\circ} \mathrm{C}$. As shown in Fig. $2 \mathrm{~A}$, the optimum activity temperature of the recombinase was $40^{\circ} \mathrm{C}$, and the activity of the recombinase was severely inhibited when temperatures below $30^{\circ} \mathrm{C}$ and above $55^{\circ} \mathrm{C}$. The levansucrase from Bacillus methylotrophicus SK 21.002 showed the highest levan production at around $37^{\circ} \mathrm{C}$ (Zhang et al. 2014). Lower optimum temperature for levan formation of 15 ${ }^{\circ} \mathrm{C}$ was reported for levansucrase from Halomonas smyrnensis AAD6 ${ }^{\top}$ (Kirtel et al. 2018).

The effect of $\mathrm{pH}$ on the levan biosynthesis ability of the recombinant enzyme was studied at different $\mathrm{pH}$ values (4.6-5.6). The highest levan formation activity of recombinase was obtained at $\mathrm{pH} 5.2$. As shown in the Fig. 2B, the activity was rather sensitive to $\mathrm{pH}$ which was only high at $\mathrm{pH} 5.2$ but decreased sharply when $\mathrm{pH}$ below 5.0 or above $\mathrm{pH}$ 5.4. The optimum $\mathrm{pH}$ for levan synthesis was lower than that of levansucrase from Leuconostoc mesenteroides B-512 FMC (Kang et al. 2005) and levansucrase from Brenneria goodwinii (Liu et al. 2017), and their optimum pH values were 6.2 and 6.0, respectively. The optimal pH for most levansucrases is between 5.0 and 6.5 (Belghith et al. 2012).

The effects of different concentrations and different kinds of metal ions on the levan formation activity of levansucrase were determined at pH 5.2 and $40{ }^{\circ} \mathrm{C}$ (Fig. 2C). $50 \mathrm{mM} \mathrm{Ca}^{2+}$ and $\mathrm{K}^{+}$increased the activity to around $130 \%$ of the initial relative activity. However, metal ions such as $\mathrm{Cu}^{2+}, \mathrm{Fe}^{3+}$ and $\mathrm{Zn}^{2+}$ had an obvious inhibitory effect on the enzyme activity indicating that the recombinase was sensitive to the presence of $\mathrm{Cu}^{2+}, \mathrm{Fe}^{3+}$ and $\mathrm{Zn}^{2+}$. Levansucrase from Bacillus methylotrophicus SK 21.002 was tested for effects on metal ions on levan biosynthesis. $20 \mathrm{mM} \mathrm{Mg}^{2+}$ increased the enzyme activity to $115 \%$ of the 
initial relative activity, while $\mathrm{Cu}^{2+}, \mathrm{Fe}^{2+}$, and $\mathrm{Zn}^{2+}$ had a strong inhibitory effect on the enzyme activity (Zhang et al. 2014). $\mathrm{Hg}^{2+}$ and $\mathrm{Ag}^{+}$decreased the activity of levansucrase from Leuconostoc Mesenteroides B-512 FMC by $92 \%$ and $86 \%$, respectively, while $\mathrm{Zn}^{2+}, \mathrm{Fe}^{2+}$ and $\mathrm{Cu}^{2+}$ slightly inhibited the activity of levansucrase (Kang et al. 2005).

Levan biosynthesis was carried out from $10 \%(\mathrm{w} / \mathrm{v})$ sucrose at pH 5.2 and $40{ }^{\circ} \mathrm{C}$, using the recombinant levansucrase of $6.45 \mathrm{U} / \mathrm{g}$ sucrose. The highest production reached to $30.6 \mathrm{~g} / \mathrm{L}$ after $2 \mathrm{~h}$, which was higher than $15 \mathrm{~g} / \mathrm{L}$ for Erwinia herbicolaand (Shih et al. 2005) and lower than $36 \mathrm{~g} / \mathrm{L}$ for B. polymyxa (NRRL B18475) (Han and Clarke 1990).

\subsection{Enzyme kinetics}

Different concentrations of sucrose solution were prepared with sodium acetate-acetate buffer. The reaction rate of levansucrase with different concentrations of sucrose solution was determined according to the method described in 2.5. According to the regression equation(Fig. 3), the Michaelis constant of levansucrase to sucrose was $25.63 \mathrm{mM}$. The $\mathrm{Km}$ value of the enzyme in this study was similar to the $\mathrm{Km}$ value (24mM) of the levansucrase from Leuconostoc mesenteroides NTM048 (Ishida et al. 2016). Moreover, the $\mathrm{Km}$ value was much lower than that of levansucrase from Halomonas smyrnensis AAD6 ${ }^{\top}$ $(104.79 \pm 4.17 \mathrm{mM})$ (Kirtel et al. 2018). Therefore, the affinity of levansucrase from different microbial sources to sucrose is very different.

\subsection{Monosaccharide Composition Analysis}

Monosaccharide composition analysis usually requires hydrolysis of polysaccharides or oligosaccharides with appropriate acids before derivatization for gas chromatography (GC) and highperformance liquid chromatography (HPLC) analysis, or high-performance ion chromatography (HPIC) analysis without derivatization. The resulting chromatogram is shown in Fig. 4. By comparing the retention time of sample monosaccharides with that of standard monosaccharides, it was determined that the sample polysaccharide was mainly composed of fructose and glucose, which accounted for $81.6 \%$ and $16.6 \%$, respectively. This was consistent with the results of levan by Levansucrase from Bacillus Methylotrophicus SK 21.002 (Zhang et al. 2014). The monosaccharide composition of polysaccharides is related to many factors, such as the hydrolysis temperature of the sample can affect the extraction of ketose. When the temperature was $30-70^{\circ} \mathrm{C}$, the free fructose was relatively stable; when the temperature rose to $120^{\circ} \mathrm{C}$, the free fructose would rapidly degrade to $80 \%$ (Dong et al. 2015).

\subsection{Molecular weight and purity of levan}

Gel permeation chromatography is the most commonly used method to detect the purity and molecular weight of polysaccharides. The molecular weight of levan was obtained by comparing the retention time of levan with the standard substance with different molecular weights. The retention time of levan was 16.667 min and it has a single elution peak in gel permeation chromatography (Fig. 5), indicating that the polymer is a homogeneous component. Based on the linear regression curve of PEG standards, the 
average molecular weight of levan was $1.56 \times 10^{6} \mathrm{Da}$ by calculation. In general, the molecular weight of polysaccharides is related to many factors, including strain type, fermentation conditions, medium composition, and extraction method. Malang et al. (2015) have shown levans synthesized by raffinose as carbon source in W. confusa E5/2 - 1 have higher molecular weight than levans synthesized from sucrose. Levan produced by Bacillus subtilis was reported to have two levan distributions: a high molecular weight levan $\left(2.3 \times 10^{6} \mathrm{Da}\right)$ and a low molecular weight levan $\left(7.2 \times 10^{3} \mathrm{Da}\right)$ (Raga-Carbajal et al. 2016). The molecular weight of levan in this study is between the two. Levan with different molecular weights has different applications in medicine, cosmetics and food. For example, levan with low $\mathrm{Mw}$ produced from Z. Mobilis had a stronger antibacterial inhibition in vitro, while levan with high $\mathrm{Mw}$ produced from Bacillus subtilis NRC1aza had the strongest DPPH free radical scavenging activity (Porras-Dominguez et al. 2015).

\subsection{SEM analysis}

A scanning electron microscopy analysis was performed to observe the microstructure and surface morphology of the levan, which can help in understanding the physical properties of the levan. The surface morphology micrographs of levan at 400x, 1000x, 2000x were shown in Fig. 6. As observed by SEM images, levan in this study had a highly branched and porous structure. It was supposed that levan with a highly branched and porous structure was conducive to the formation of hydrated polymers and was most likely to be used in foods and cosmetics industries as texturing, thickening, stabilizing, and water-binding agent (Sun et al. 2018; Yang et al. 2018; Zhou et al. 2018). Besides, SEM images indicated that levan had a sheet-like smooth and glossy surface, which had the potential to prepare plasticized film (Feng et al. 2018). The part microstructure of the levan in this study was similar to the microstructure of glucan produced by Leuconostoc pseudomesenteroides XG5, which had a smooth and glittering surface and high branched structure (Zhou et al. 2018), but there were a little differences between levan from Bacillus mojavensis and Brenneria sp. EniD312 exhibited uniform porous network (Haddar et al. 2021; Xu et al. 2018).

\subsection{AFM analysis}

AFM is a useful tool for characterizing polymer morphology with high resolution and simple operation, which is developed on the basis of SEM. The topographical AFM images of levan exhibited many ellipsoidal or spheroidal particles and spike-like lumps (Fig. 7), which indicated that polysaccharides had a strong affinity with water molecules (Ahmed et al. 2013; Wang et al. 2019a; Xu et al. 2018). The maximum peak height of rounded lumps was $55.7 \mathrm{~nm}$, the average roughness was $3.41 \mathrm{~nm}$ and the mean roughness was $1.48 \mathrm{~nm}$. The maximum height of levan was much higher than the height of a single polysaccharide chain $(0.1-1 \mathrm{~nm})$ suggesting that the tightly packed molecular structure formed in AFM images may be caused by the intermolecular and intramolecular aggregation of levan (Sun et al. 2018). A similar result was reported for the EPS polymer from Lactobacillus sakei L3 (Wang et al. 2019b) but 
different from Lactobacillus reuteri E81 glucan which had the tangled networks (Ispirli et al. 2019) and Mesona blumes gum EPS polymer which had an irregular shape like the worm (Tao et al. 2008).

\subsection{FT-IR analysis}

Fourier-transformed infrared spectroscopy is used to determine the glycoside bond configuration and the functional group on the sugar chain by using the relative vibrations within the molecule and molecular rotation information to analyze the structure of polysaccharides. Figure 8 showed the FT-IR spectrum of purified levan. The wide and strong peak at $3304 \mathrm{~cm}^{-1}$ was caused by the stretching vibration of $\mathrm{O}-\mathrm{H}$ (Moussa et al. 2017; Zhang et al. 2014), indicating the existence of intermolecular hydrogen bonding. The weak peaks at $2931 \mathrm{~cm}^{-1}$ and $2887 \mathrm{~cm}^{-1}$ were the results of $\mathrm{C}-\mathrm{H}$ stretching vibration and bending vibration respectively (Yu et al. 2016). The strong absorption peak at $1644 \mathrm{~cm}^{-1}$ was caused by the $\mathrm{O}-\mathrm{H}$ bending vibration, which might be caused by the presence of water in the sample (Hao et al. 2016). The absorption peaks at $1122 \mathrm{~cm}^{-1}$ and $1009 \mathrm{~cm}^{-1}$ were caused by C-O-C stretching vibration (Guo et al. 2013), which were the characteristic peaks of carbohydrates. The absorption peaks at $923 \mathrm{~cm}^{-1}$ and 809 $\mathrm{cm}^{-1}$ represented symmetric stretching vibration of furanose and D-type C-H bending vibration of furanose respectively, which were typical signal peaks of furanose (Cai et al. 2019; Ni et al. 2018). Thus it was proved that a furan ring was contained in the polysaccharide structure. Preliminary analysis showed that the polysaccharide was composed of D-furanose.

\subsection{NMR analysis}

Nuclear magnetic resonance spectroscopy was introduced into the study and analysis area of sugar chemistry in the 1970s and played a great role in the analysis of polysaccharides with complex structures. Further analysis of the structure of purified polysaccharides was obtained by ${ }^{1} \mathrm{H}$ and ${ }^{13} \mathrm{C} \mathrm{NMR}$ spectra.

According to the ${ }^{13} \mathrm{C}$ NMR spectra (Fig. 9A), the six obvious resonance signals were $104.19 \mathrm{ppm}$ (C2), 80.27 ppm (C5), 76.28 ppm (C3), 75.18 ppm (C4), 63.36 ppm (C6), 59.88 ppm (C1), respectively. The 6 peaks proved that the monosaccharide component of this polysaccharide was hexose. The anomeric carbon signal region is usually located between 95 and 110 ppm, and the ring carbon signal region is located between 50 and 85 ppm. There was an obvious absorption peak of $104.19 \mathrm{ppm}$ (C2) in the anomeric carbon region, which was the characteristic signal of $\beta$-configuration (Nasir et al. 2015). The signal at the $63.36 \mathrm{ppm}$ (C6) confirmed the presence of the fructose $\beta-(2,6)$-linkage (Mamay et al. 2015). The chemical shift between $\mathrm{C} 1$ and $\mathrm{C} 6$ of inulin was usually very close, while that of levan's ring carbons (C3, C4, C5) were very close (Bouallegue et al. 2020b). These carbon chemical shifts of levan produced by levansucrase reported in other literatures were shown in Table 1, which were similar to the six signals in this paper.

According to the ${ }^{1} \mathrm{H}$ NMR spectra (Fig. 9B), seven major proton signals were observed at $4.10 \mathrm{ppm}(\mathrm{H} 3)$, 4.01 ppm (H4), 3.87 ppm (H5), 3.82 ppm (H6a), 3.68 ppm (H1a), 3.60 ppm (H1b), and 3.48 ppm (H6b), 
respectively. All of them were in the ring proton region (3.4-4.2 ppm) indicating that the polysaccharide was composed of ketose (Cai et al. 2019; Yu et al. 2016). The ratio of peak areas was approximately 1:1:1:1:1:1:1 which meant the same amount of every kind of $\mathrm{H}$ atom. All the information indicated that the product synthesized by levansucrase was $\beta-(2,6)$ levan.

\section{Conclusion}

In this study, levan was synthesized in vitro with recombinant levansucrase from Bacillus subtilis ZW019 strain. The yield of levan reached $30.6 \mathrm{~g} / \mathrm{L}$. The synthesized levan has a molecular weight of $1.56 \times 10^{6} \mathrm{Da}$, and its structure is $\beta-(2,6)$ fructose, containing furan ring. The results indicated that the genetically engineered $E$. coli strain could express levansucrase efficiently, and the recombinant levansucrase could be easily purified in one step. Moreover, the recombinant levansucrase showed high catalytic activity in vitro, and the composition and structure of the synthesized levan were highly similar to that of natural levan. In the future, we will further study the biological function of the levan synthesized by enzymatic method, and then explore the application way of the levan.

\section{Declarations}

\section{Acknowledgements}

Jingyue Wang: Conceptualization, Methodology, Investigation, Writing - Original Draft.

Xinan Xu: Conceptualization, Methodology, Investigation, Writing - Original Draft.

Fangkun Zhao: Investigation, Writing - Review \& Editing, Formal analysis.

Nan Yin: Investigation, Formal analysis.

Zhijiang Zhou: Supervision, Software.

Ye Han*: Resources, Supervision, Project administration, Funding acquisition.

\section{Funding}

This work was financially supported by the Key Technology R\&B Program of Tianjin,China (19YFZCSN00100).

\section{Conflict of interest}

The authors declare no conflict of interest and unanimously approve publication of the manuscript.

\section{References}


Ahmed Z, Wang Y, Anjum N, Ahmad A, Khan ST (2013) Characterization of exopolysaccharide produced by Lactobacillus kefiranofaciens ZW3 isolated from Tibet kefir-Part II. Food Hydrocolloids 30(1):343-350

Barone JR, Medynets M (2007) Thermally processed levan polymers. Carbohydr Polym 69(3):554-561

Belghith KS, Dahech I, Belghith H, Mejdoub H (2012) Microbial production of levansucrase for synthesis of fructooligosaccharides and levan. Int J Biol Macromol 50:451-458

Bouallegue A, Casillo A, Chaari F, Cimini D, Corsaro MM, Bachoual R, Ellouz-Chaabouni S (2020a) Statistical optimization of levan: Influence of the parameter on levan structure and angiotensin Iconverting enzyme inhibitory. Int J Biol Macromol 158:945-952

Bouallegue A, Casillo A, Chaari F, La Gatta A, Lanzetta R, Corsaro MM (2020b) Levan from a new isolated Bacillus subtilis AF17: Purification, structural analysis and antioxidant activities. Int J Biol Macromol 144:316-324

Cai G, Liu Y, Li X, Lu J (2019) New Levan-Type Exopolysaccharide from Bacillus amyloliquefaciens as an Antiadhesive Agent against Enterotoxigenic Escherichia coli. J Agric Food Chem 67:8029-8034

Chiang CJ, Wang JY, Chen PT, Chao YP (2009) Enhanced levan production using chitin-binding domain fused levansucrase immobilized on chitin beads. Appl Microbiol Biotechnol 82(3):445-451

Dong CX, Zhang LJ, Xu R, Zhang G, Zhou YB, Han XQ (2015) Structural characterization and immunostimulating activity of a levan-type fructan from Curcuma kwangsiensis. Int $\mathrm{J}$ Biol Macromol 77:99-104.

Esawy MA, Ahmed EF, Helmy WA, Mansour NM, El-Senousy WM, El-Safty MM (2011) Production of levansucrase from novel honey Bacillus subtilis isolates capable of producing antiviral levans. Carbohydr Polym 86:823-830.

Feng F, Zhou Q, Yang Y, Zhao F, Du R, Han Y, Xiao H, Zhou Z (2018) Characterization of highly branched dextran produced by Leuconostoc citreum B-2 from pineapple fermented product. Int J Biol Macromol 113:45-50

Guo S, Mao W, Li Y, Gu Q, Chen Y, Zhao C, Li N, Wang C, Guo T, Liu X (2013) Preparation, structural characterization and antioxidant activity of an extracellular polysaccharide produced by the fungus Oidiodendron truncatum GW. Process Biochemistry 48(3):539-544

Haddar A, Hamed M, Bouallegue A, Bastos R, Coelho E, Coimbra MA (2021) Structural elucidation and interfacial properties of a levan isolated from Bacillus mojavensis. Food Chem 343:128456

Han YW, Clarke MA (1990) Production and characterization of microbial levan. J Agric Food Chem 38:393-396 
Hao L, Sheng Z, Lu J, Tao R, Jia S (2016) Characterization and antioxidant activities of extracellular and intracellular polysaccharides from Fomitopsis pinicola. Carbohydr Polym 141:54-59

Ishida R, Sakaguchi K, Matsuzaki C, Katoh T, Ishida N, Yamamoto K, Hisa K (2016) Levansucrase from Leuconostoc mesenteroides NTM048 produces a levan exopolysaccharide with immunomodulating activity. Biotechnol Lett 38:681-687

İspirli H, Sagdic O, Yılmaz MT, Dertli E (2019) Physicochemical characterisation of an a-glucan from Lactobacillus reuteri E81 as a potential exopolysaccharide suitable for food applications. Process Biochemistry 79:91-96

Jang KH, Song KB, Kim CH et al (2001) Comparison of characteristics of levan produced by different preparations of levansucrase from Zymomonas mobilis. Biotechnol Lett 23:339-344.

Kang HK, Seo MY, Seo ES et al (2005) Cloning and expression of levansucrase from Leuconostoc mesenteroides B-512 FMC in Escherichia coli. Biochim Biophys Acta 1727(1):5-15

Kirtel O, Menendez C, Versluys M, Van den Ende W, Hernandez L, Toksoy Oner E (2018) Levansucrase from Halomonas smyrnensis AAD6 ${ }^{\top}$ : first halophilic GH-J clan enzyme recombinantly expressed, purified, and characterized. Appl Microbiol Biotechnol 102(21):9207-9220

Liu Q, Yu S, Zhang T, Jiang B, Mu W (2017) Efficient biosynthesis of levan from sucrose by a novel levansucrase from Brenneria goodwinii. Carbohydr Polym 157:1732-1740

Malang SK, Maina NH, Schwab C, Tenkanen M, Lacroix C (2015) Characterization of exopolysaccharide and ropy capsular polysaccharide formation by Weissella. Food Microbiol 46:418-427

Mamay, Wahyuningrum D, Hertadi R (2015) Isolation and Characterization of Levan from Moderate Halophilic bacteria Bacillus licheniformis BK AG21. Procedia Chemistry 16:292-298

Miller GL (1959) Modified DNS method for reducing sugars. Anal Chem 31:426-428

Moussa TAA, Al-Qaysi SAS, Thabit ZA, Kadhem SB (2017) Microbial levan from Brachybacterium phenoliresistens: Characterization and enhancement of production Process Biochemistry 57:9-15

Nasir DQ, Wahyuningrum D, Hertadi R (2015) Screening and Characterization of Levan Secreted by Halophilic Bacterium of Halomonas and Chromohalobacter Genuses Originated from Bledug Kuwu Mud Crater. Procedia Chemistry 16:272-278

Ni D, Xu W, Bai Y, Zhang W, Zhang T, Mu W (2018) Biosynthesis of levan from sucrose using a thermostable levansucrase from Lactobacillus reuteri LTH5448. Int J Biol Macromol 113:29-37

Poli A, Kazak H, Gürleyendağ B, Tommonaro G, Pieretti G, Öner ET, Nicolaus B (2009) High level synthesis of levan by a novel Halomonas species growing on defined media. Carbohydr Polym 78(4):651-657 
Porras-Dominguez JR, Avila-Fernandez A, Miranda-Molina A, Rodriguez-Alegria ME, Munguia AL (2015) Bacillus subtilis 168 levansucrase (SacB) activity affects average levan molecular weight. Carbohydr Polym 132:338-344

Raga-Carbajal E, Carrillo-Nava E, Costas M, Porras-Dominguez J, Lopez-Munguia A, Olvera C (2016) Size product modulation by enzyme concentration reveals two distinct levan elongation mechanisms in Bacillus subtilis levansucrase. Glycobiology 26(4):377-385.

Shih IL, Chen LD, Wu JY (2010) Levan production using Bacillus subtilis natto cells immobilized on alginate. Carbohydr Polym 82(1):111-117

Shih I, Yu Y, Shieh C, Hsieh C (2005) Selective production and characterization of levan by Bacillus subtilis (Natto) Takahashi. J Agric Food Chem 53:8211-8215

Srikanth R, Reddy CH, Siddartha G, Ramaiah MJ, Uppuluri KB (2015a) Review on production, characterization and applications of microbial levan. Carbohydr Polym 120:102-114

Srikanth R, Siddartha G, Sundhar Reddy CH, Harish BS, Janaki Ramaiah M, Uppuluri KB (2015b) Antioxidant and anti-inflammatory levan produced from Acetobacter xylinum NCIM2526 and its statistical optimization. Carbohydr Polym 123:8-16.

Sun N, Liu H, Liu S et al (2018) Purification, Preliminary Structure and Antitumor Activity of Exopolysaccharide Produced by Streptococcus thermophilus $\mathrm{CH}$. Molecules 23(11)

Tao F, Biao GZ, Yu JZ, Ning ZH (2008) Isolation and characterization of an acidic polysaccharide from Mesona Blumes gum. Carbohydr Polym 71(2):159-169

Wang B, Song Q, Zhao F, Xiao H, Zhou Z, Han Y (2019a) Purification and characterization of dextran produced by Leuconostoc pseudomesenteroides $\mathrm{PC}$ as a potential exopolysaccharide suitable for food applications. Process Biochemistry 87:187-195

Wang B, Song Q, Zhao F, Zhang L, Han Y, Zhou Z (2019b) Isolation and characterization of dextran produced by Lactobacillus sakei L3 from Hubei sausage. Carbohydr Polym 223: 115111

Wang J, Xiao H, Zhao F, Zhao B, Xu M, Zhou Z, Han Y (2021) A Fructan Sucrase Secreted Extracellular and Purified in One-Step by Gram-Positive Enhancer Matrix Particles. Processes 9(1):95

Xavier JR, Ramana KV (2017) Optimization of Levan Production by Cold-Active Bacillus licheniformis ANT 179 and Fructooligosaccharide Synthesis by Its Levansucrase. Appl Biochem Biotechnol 181(3):9861006

Xu W, Liu Q, Bai Y, Yu S, Zhang T, Jiang B, Mu W (2018) Physicochemical properties of a high molecular weight levan from Brenneria sp. EniD312. Int J Biol Macromol 109:810-818 
Yamamoto Y, Takahashi, Y, Kawano M, lizuka M, Matsumoto T, Saeki S, Yamaguchi H (1999) In vitro digestibility and fermentability of levan and its hypocholesterolemic effects in rats. J Nutr Biochem 10:13-18.

Yang Y, Feng F, Zhou Q, Zhao F, Du R, Zhou Z, Han Y (2018) Isolation, purification and characterization of exopolysaccharide produced by Leuconostoc pseudomesenteroides YF32 from soybean paste. Int J Biol Macromol 114:529-535

Yu X, Li L, Zhang J, Shen Z, Zhu C, Wang P, Jiang X (2016) Structural analysis of macromolecular levan produced by Bacillus megaterium GJT321 based on enzymatic method. Int J Biol Macromol 93:10801089

Zhang T, Li R, Qian H, Mu W, Miao M, Jiang B (2014) Biosynthesis of levan by levansucrase from Bacillus methylotrophicus SK 21.002. Carbohydr Polym 101:975-981

Zhao F, Song Q, Wang B, Han Y, Zhou Z (2020) Purification and immobilization of the soluble and insoluble portions of recombinant lipase by gram-positive enhancer matrix (GEM) particles. Int J Biol Macromol 145:1099-1105

Zhou Q, Feng F, Yang Y, Zhao F, Du R, Zhou Z, Han Y (2018) Characterization of a dextran produced by Leuconostoc pseudomesenteroides XG5 from homemade wine. Int J Biol Macromol 107:2234-2241

\section{Tables}

Table $1^{13} \mathrm{C}$ chemical shifts of levans produced by different levansucrases.

\begin{tabular}{|llllllll|}
\hline Microorganisms & C1 & C2 & C3 & C4 & C5 & C6 & References \\
\hline Lactobacillus reuteri LTH5448 & 60.93 & 104.55 & 77.25 & 75.90 & 80.66 & 63.81 & $\begin{array}{l}\text { (Ni et al., } \\
\text { 2018) }\end{array}$ \\
\hline $\begin{array}{l}\text { Leuconostoc mesenteroides } \\
\text { NTM048 }\end{array}$ & 59.91 & 104.24 & 76.30 & 75.22 & 80.33 & 63.44 & $\begin{array}{l}\text { (Ishida et } \\
\text { al., 2016) }\end{array}$ \\
$\begin{array}{l}\text { Bacillus licheniformis ANT } \\
179\end{array}$ & 62.58 & 106.80 & 78.96 & 77.83 & 82.89 & 65.99 & $\begin{array}{l}\text { (Xavier \& } \\
\text { Ramana, } \\
\text { 2017) }\end{array}$ \\
\hline $\begin{array}{l}\text { Bacillus methylotrophicus SK } \\
21.002\end{array}$ & 61.20 & 104.66 & 77.51 & 76.10 & 80.77 & 63.94 & $\begin{array}{l}\text { (Zhang et } \\
\text { al., 2014) }\end{array}$ \\
\hline \begin{tabular}{l} 
Bacillus subtilis ZW019 \\
\hline
\end{tabular} & 59.88 & 104.19 & 76.28 & 75.18 & 80.27 & 63.36 & this study \\
\hline
\end{tabular}

\section{Figures}




\section{M \\ 1}

\section{KDa}

$58 \mathrm{KDa}$

\section{Figure 1}

The levansucrase was purified by GEM. Lanes: $\mathrm{M}$, molecular mass standards; 1 『Purified intracellular recombinant levansucrase. 

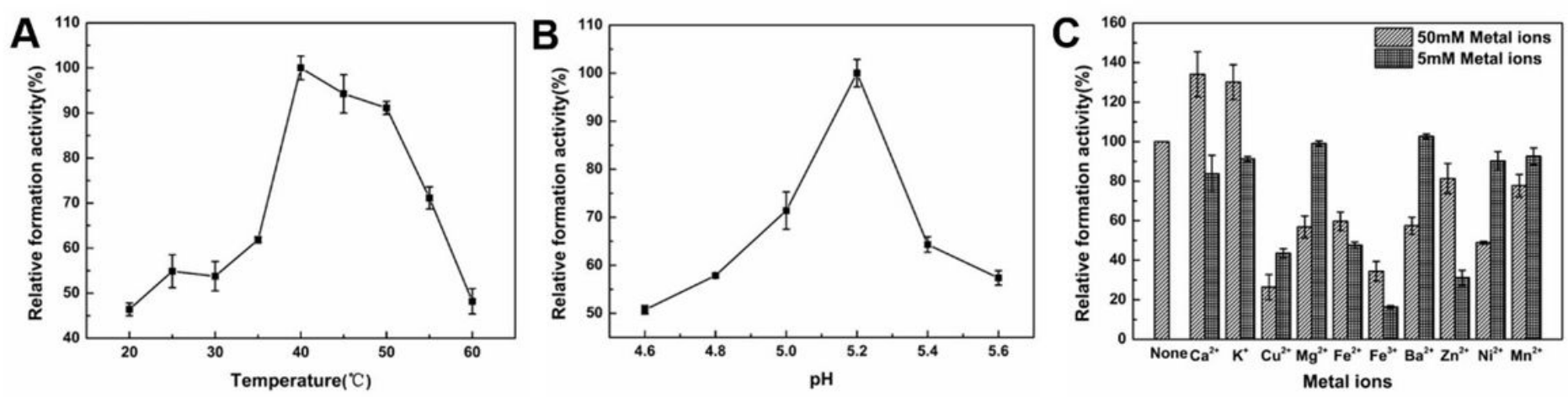

Figure 2

Effect of temperature (A), $\mathrm{pH}(\mathrm{B})$, metal ions (C) on the levan formation activity of recombinant levansucrase.

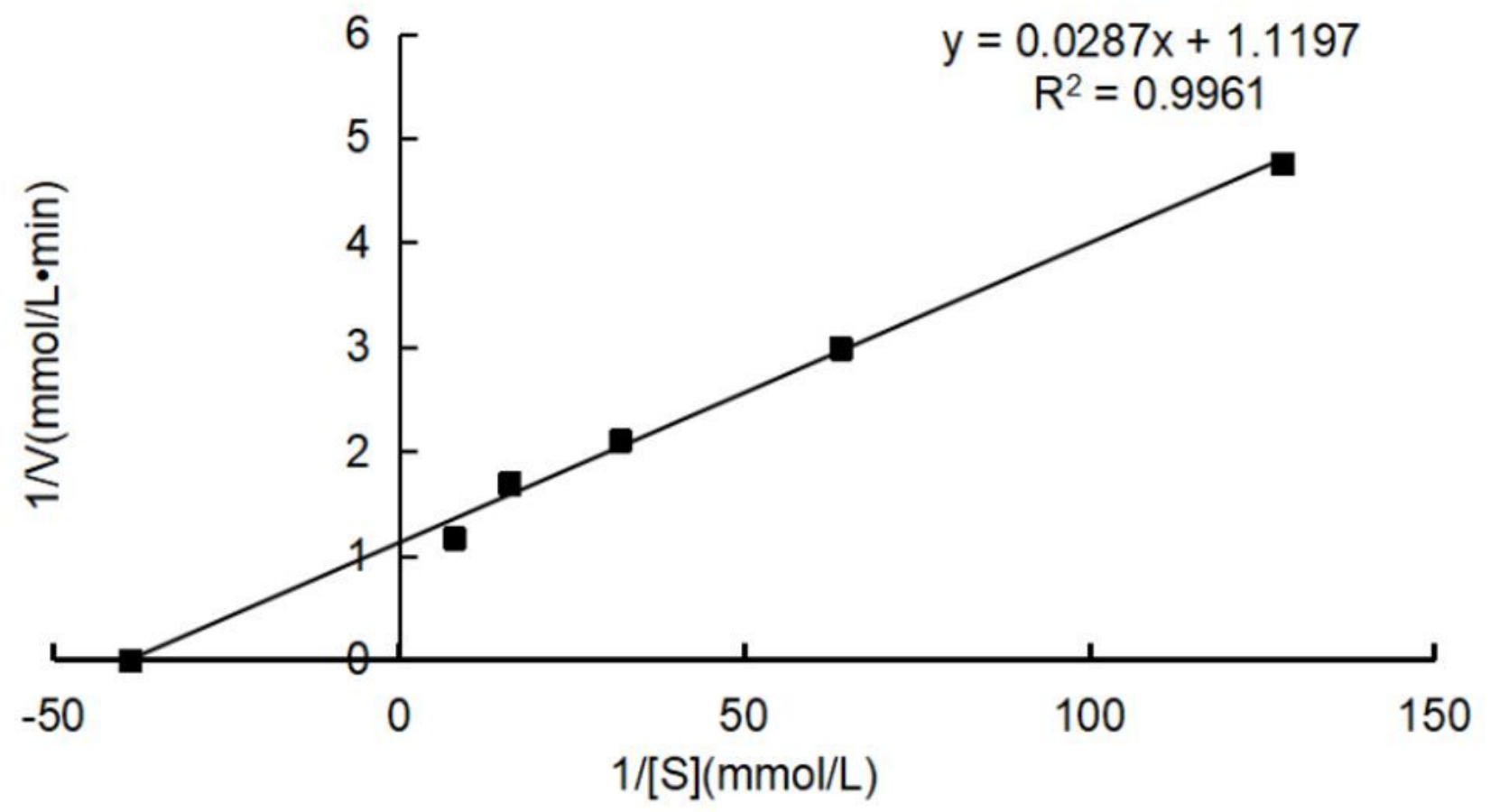

Figure 3

Michaelis-Menten kinetic parameters 


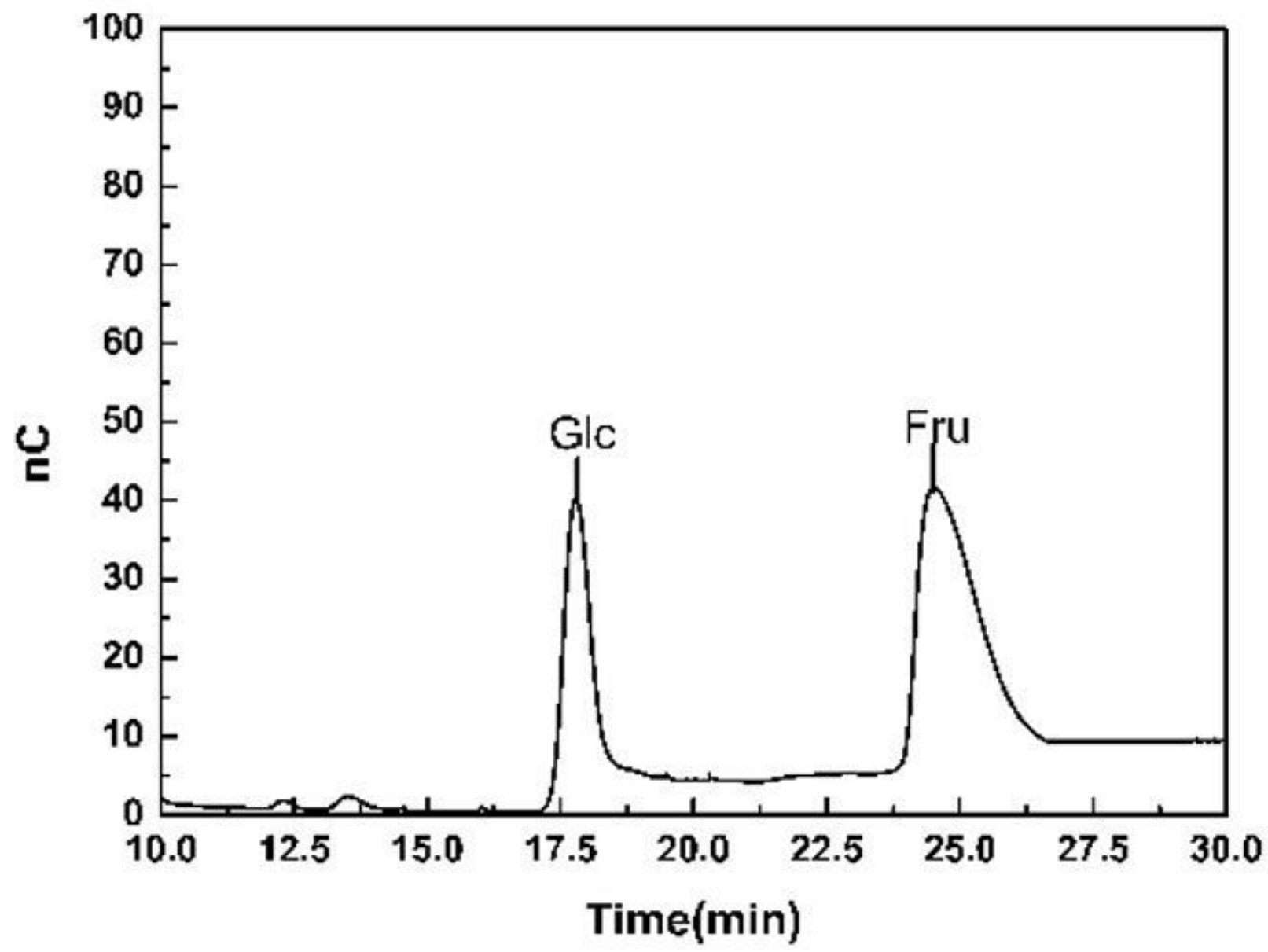

Figure 4

Sugar analysis spectrum of purified levan. 


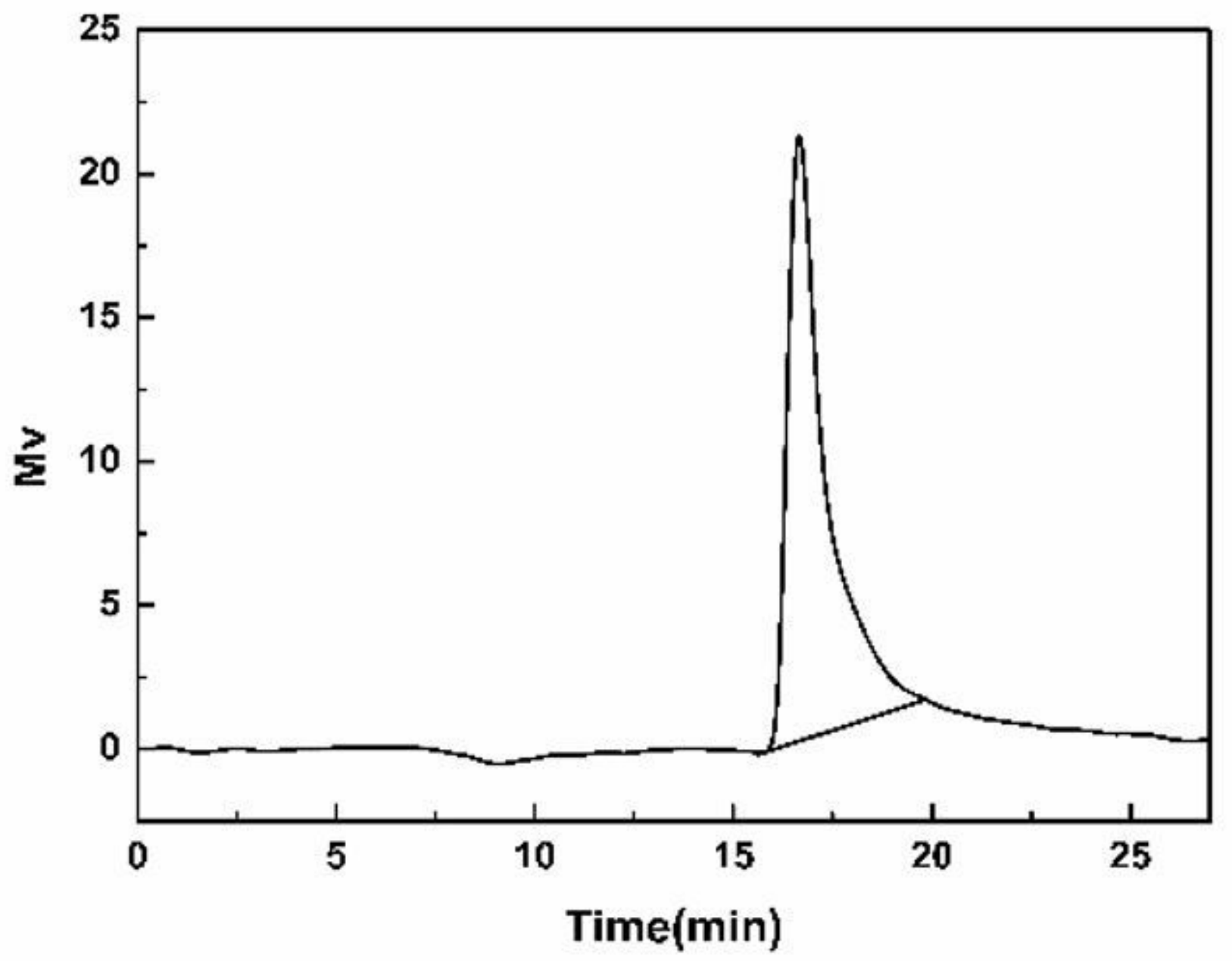

Figure 5

Gel permeation chromatography of purified levan. 


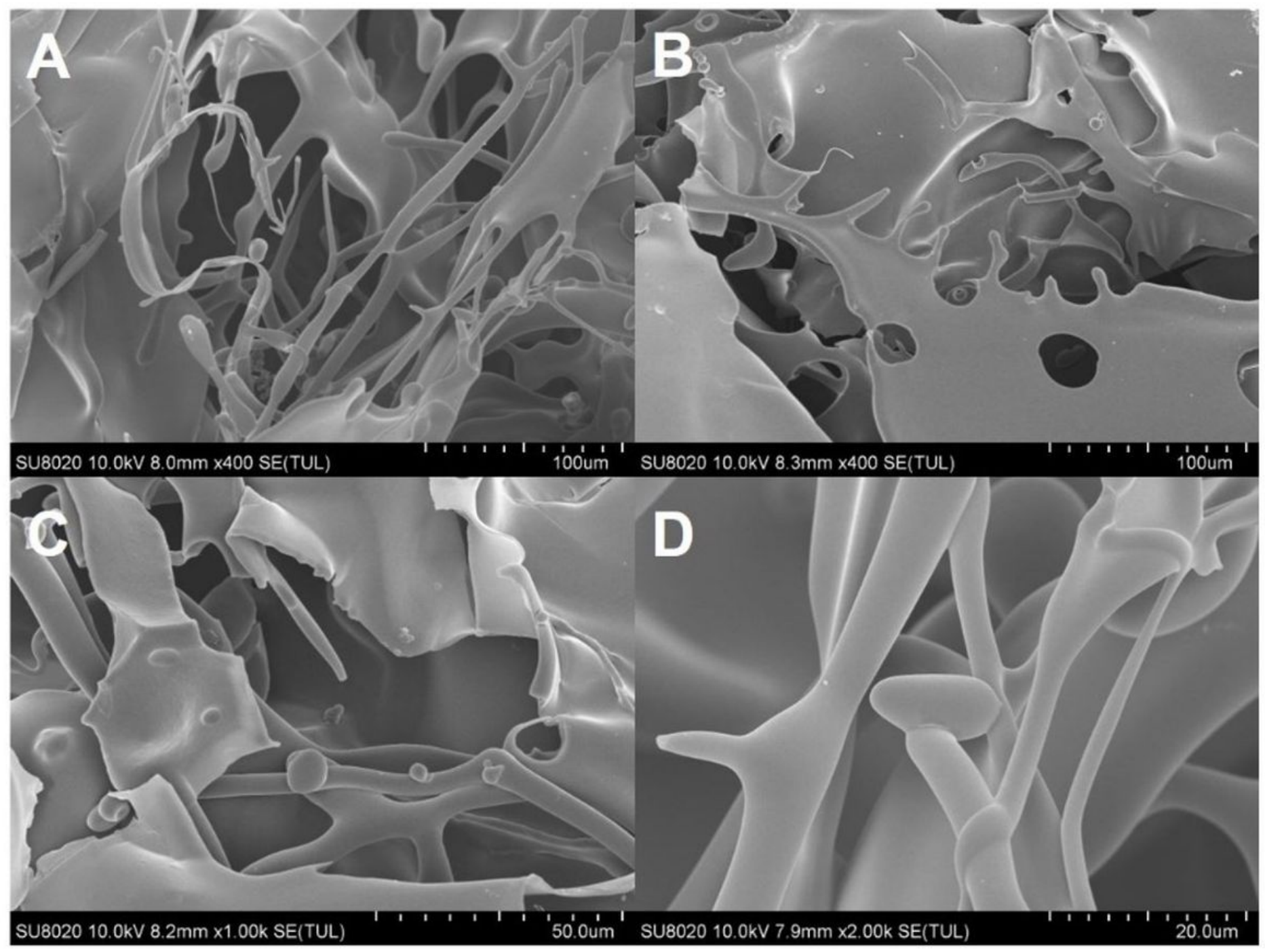

Figure 6

SEM images of purified levan at $400 \times(A, B), 1000 \times(C), 2000 \times(D)$ magnification. 


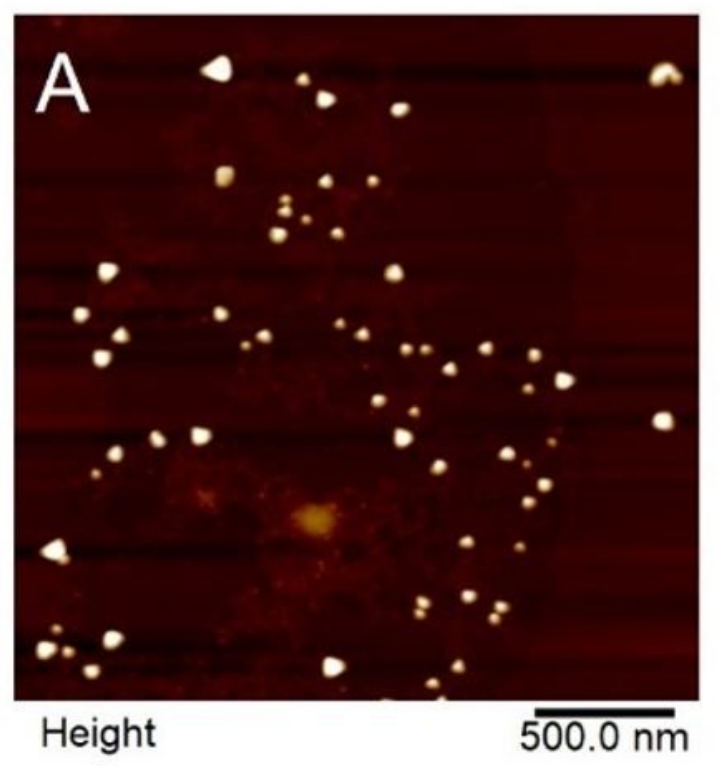

\section{B}

$24.5 \mathrm{~nm}$
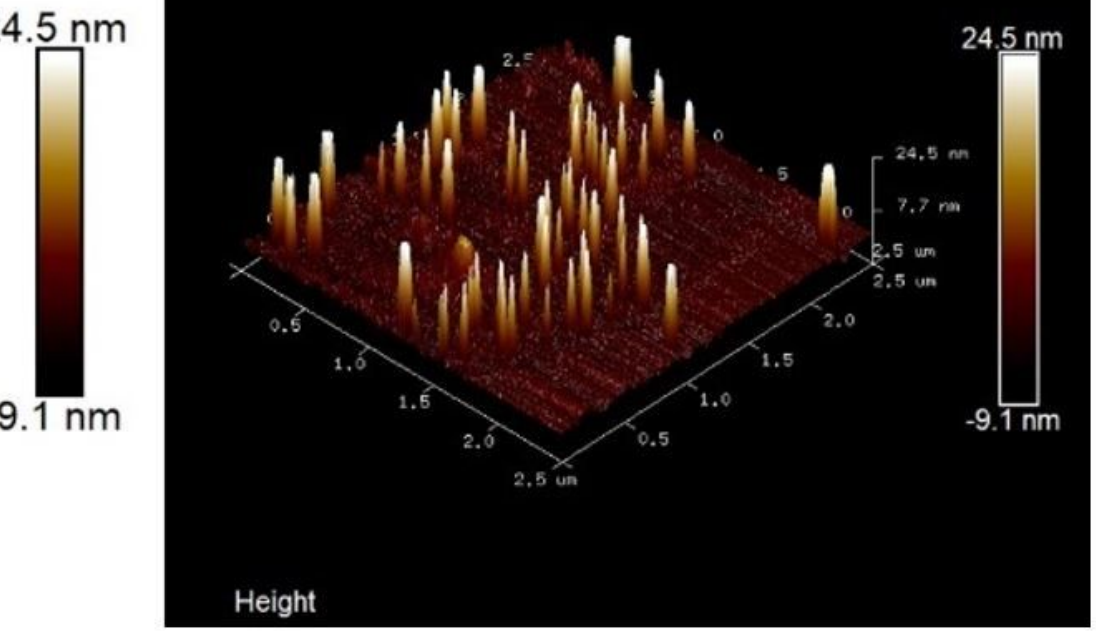

Figure 7

AFM images of purified levan (A) planar and (B) cubic.

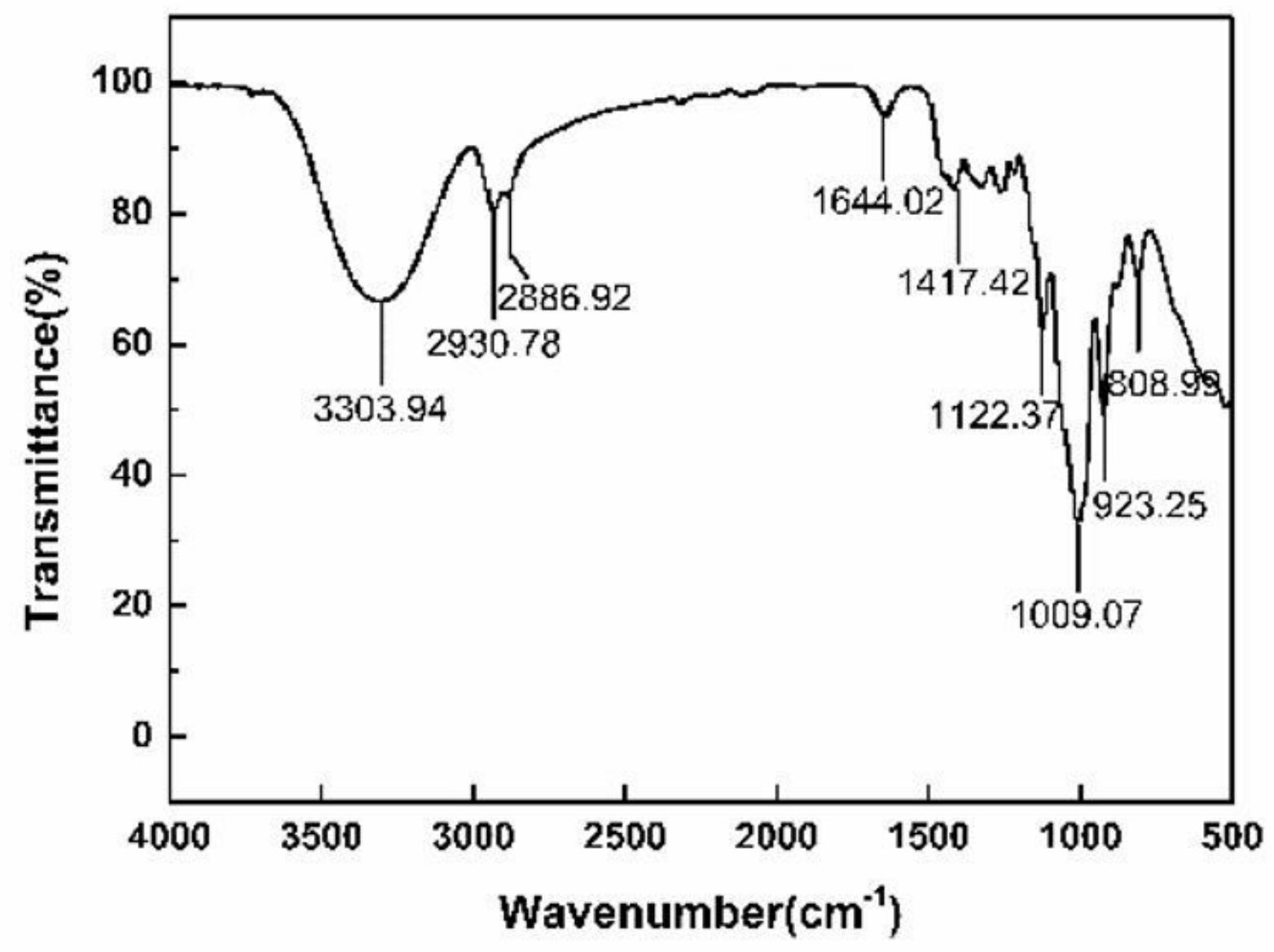


Figure 8

FT-IR spectra of purified levan.
A

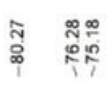
ఊ్ల్ల

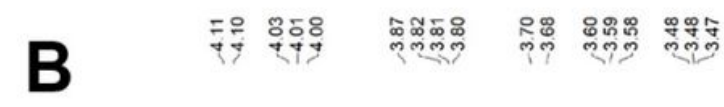
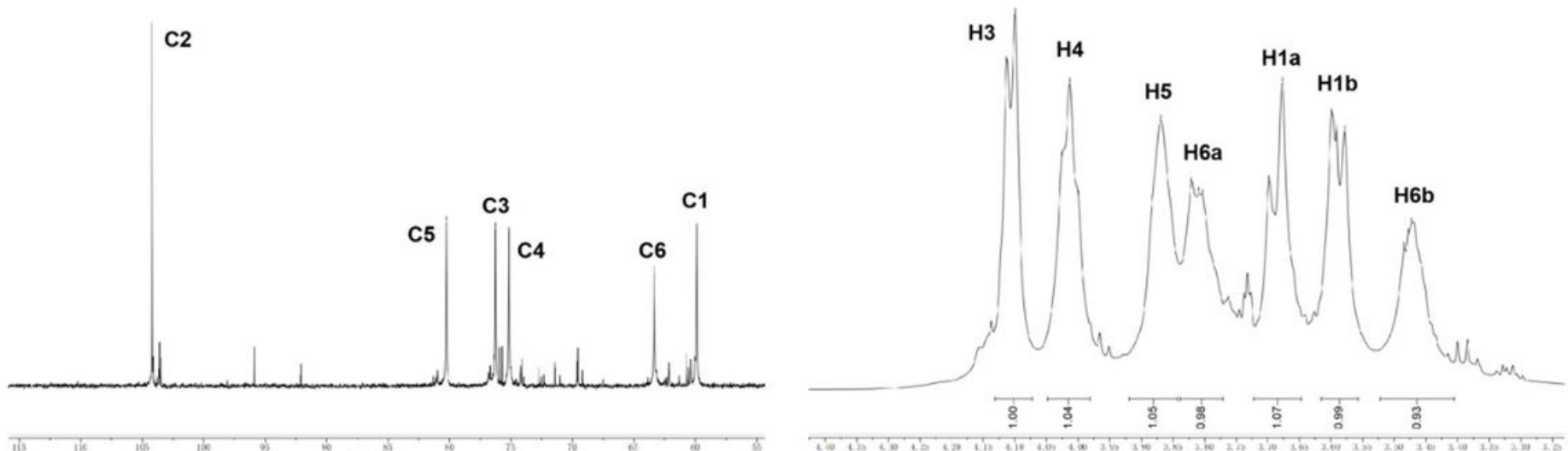

Figure 9

(A) 1D 13C and (B) 1H NMR spectra of purified levan. 